\title{
Jociele Lampert
}

\section{0 ateliê de pintura como um laboratório de ensino e aprendizagem em Artes Visuais}

\section{Resumo}

0 ateliê de pintura como um laboratório de ensino e aprendizagem em Artes Visuais é um projeto de pesquisa desenvolvido na Universidade do Estado de Santa Catarina, em Florianópolis, Brasil. O projeto apresenta perspectivas da pesquisa em Arte e Arte Educação no campo das Artes Visuais. Refere-se ao espaço/ tempo das ações desenvolvidas no ateliê de pintura no contexto da Universidade e aponta como lugar de investigação e reflexão o Grupo de Estudos Estúdio de Pintura Apotheke. Abordam-se não somente metodologias operativas, mas a dimensão da experiência e a sua intensidade e potência, compreendendo assim o "entre" (como caminho formativo) em paisagens pedagógicas e artísticas. No contexto do ensino de pintura, o espaço de um grupo de estudos busca construir tessituras para o ensino e a aprendizagem; intenciona perceber a experiência como processo de deslocamento. 0 eixo teórico do projeto situa-se nos escritos de Dewey (2010), Sullivan (2004), Lampert $(2009,2016)$ e Lampert \& Wosniak (2016).

\section{Palavras-chave}

Experiência. Artista professor. Pesquisa em Arte e Arte Educação. 


\section{DETALHANDO O CONTEXTO}

Este projeto de pesquisa se trata de um adensamento da Tese de Doutorado em Artes Visuais defendida em 2009 na Escola de Comunicações e Artes da USP, no Brasil, cujo objetivo consistiu no estudo da formação docente, Arte Contemporânea e cultura visual. Passaram-se 10 anos, e desde então, tenho trabalhado efetivamente na formação de artistas professores na Universidade e, nos últimos tempos, venho considerando o eixo da prática artística como pesquisa em Arte e Arte Educação, tendo a Arte como Experiência (Dewey) como teoria base para a construção de investigações.

Diante de questões relativas às inquietações que permeiam o trabalho formativo de artistas professores na Universidade - que envolve não somente o planejamento de aulas, reflexões sobre a produção plástica e teórica, a criticidade sobre o tempo e espaço onde nos localizamos - ou de questões como se o nosso trabalho realmente "faz diferença para a formação docente e artística onde atuamos", relacionadas aos embates com a burocracia universitária - onde muitas vezes (em nosso contexto) a atividade meio é mais relevante que a atividade fim (aula e pesquisa) -, desenvolvi em 2013 um projeto de pesquisa como professora visitante na Columbia University, nos EUA. Intitulado Artist's diary and professor's diary: roaming about painting education, o projeto foi realizado sob os auspícios da Bolsa Fulbright e desenvolvido no Teachers College. Naquele espaço educativo, verifiquei a possibilidade do entrecruzamento da pesquisa da prática artística com a pesquisa educativa na Pós-Graduação. 0 espaço do ateliê e da galeria de arte, assim como a pesquisa com materiais e imagens, mostram-se fundamentais para o desenvolvimento de teorias educativas no Programa de Arte e Arte Educação, onde prática artística e a reflexão teórica, bem como a práxis de pesquisa em Arte Educação - que envolve fazer perguntas e procurar respostas que permitam melhor compreender como fazer Arte, estudar Arte e ensinar Arte - se articulam.

Quando retornei ao Brasil, sem equiparar os sistemas de ensino (porque isto seria impossível) busquei desenvolver um projeto de pesquisa que permeasse estes tópicos e, sobretudo, pudesse estender a possibilidade da prática enquanto fazer/agir/sentir com entendimento reflexivo e crítico sobre o contexto onde nos situamos. Tal questão parte não somente da perspectiva 
de mapear metodologias operativas desenvolvidas na pesquisa em Arte, mas na direção de instaurar outro modo ou paisagem, gerando deslocamentos para uma consonância contemporânea frente à Arte e à Educação que dinamize o processo formativo do artista professor.

O olhar sobre a pesquisa no ateliê de pintura parte da premissa de que o objeto artístico é gestado a partir de potências discursivas, pedagógicas e políticas (Dewey, 2010). Sendo assim, instaurar um trânsito educativo sobre a pesquisa que paire entre o artista e professor, professor e pesquisador, professor e aluno, teoria e prática, experiência e informação, real e imaginário, corpo e representação, forma e conteúdo, conhecimento e ação corresponderia a um regime sensível que cria fluxos e alarga o estranhamento dos modos de fazer pesquisa, conforme Ranciere (2015) e Jesus (2013) apontam em seus escritos.

No ateliê, além da concepção de imagens e signos, observa-se a contaminação entre quem ensina e quem aprende - e como quem ensina aprende -, além das metodologias operativas e de abordagens que examinam formas de investigações nas Artes Visuais presentes em teorias, práticas e contextos vivenciados pelos artistas. São investigações críticas e criativas que ocupam o espaço do ateliê, das galerias, museus, da internet, comunidade, e outros espaços de trabaIho do artista e do professor de Arte que tornam fértil o campo em prática artística. Neste momento, situa-se o próprio processo como o fio condutor do contexto da investigação. Dewey evidencia a relevância de entender o processo como essencial no aprendizado e a busca pela percepção e reflexão como elementos fundamentais na construção do sujeito - uma apreensão baseada na experimentação, na qual, a partir da percepção, da imaginação e da experiência, faz-se o ajuste da consciência (DEWEY, 2010). A experiência de um vínculo entre teoria e prática provoca a interação entre ideia e ação, proporcionando uma concepção de conhecimento pelo caminho do agir agindo e do fazer fazendo, criando experimentações que possibilitem condições críticas e reflexivas.

Daniel Buren (1979), no texto The Function of the Studio, do final dos anos 70 , questionou sobre a funcionalidade do estúdio para a percepção de metáforas que pairam sobre o espaço, visto que este

1. é o lugar onde o trabalho se origina.

2. em geral, é um lugar privado; uma torre de marfim, talvez.

3. é um lugar fixo onde objetos portáteis são produzidos.

A relevância do estúdio já deveria ser evidente, pois é o primeiro enquadramento (estrutura), o primeiro limite, do qual todos os enquadramentos (estruturas) subsequentes dependerão. 0 que o caracteriza fisicamente, arquitetonicamente? Para Buren, o estúdio não é um refúgio ou um quarto qualquer. $\mathrm{O}$ autor aponta dois tipos de estúdio: o tipo europeu, modelado sobre o 
estúdio parisiense da virada do século, com pé direito alto, luz natural, portas com acesso para grandes formatos e, às vezes, com varanda para ampliar o olhar entre a obra e o artista; e o estúdio americano, de origem mais recente. Este tipo de construção é raramente construída de acordo com especificações, sendo localizada em lofts renovados. É geralmente muito maior do que o tipo europeu; não necessariamente mais alto, porém mais amplo. As paredes e o piso são abundantes, e a iluminação natural desempenha um papel insignificante, uma vez que é iluminado por eletricidade dia e noite, se necessário. Há, portanto, equivalência entre os produtos/obras desses lofts e sua colocação nas paredes e pisos de museus modernos, que também são continuamente iluminados por eletricidade. Este segundo tipo de estúdio tem influenciado o estúdio europeu de hoje, seja ele localizado num antigo celeiro do interior ou num armazém abandonado no espaço urbano. Lugar privado, o estúdio é presidido pelo artista-residente, uma vez que só o trabalho que ele deseja ou permite será realizado em seu estúdio. Outras operações também acontecem no espaço e tempo do estúdio, desde a apresentação de trabalhos a críticos de arte, colecionadores e curadores, até aulas, conversas com artistas e diferentes cursos que interessem ao processo criativo.

Sendo assim, vê-se o estúdio de pintura especificamente como a própria pintura expandida, desdobrada, reprojetada, reencarnada ou ampliada, como exemplo das expressões vinculadas aos procedimentos pictóricos do tempo contemporâneo. Desta forma, intenciona-se abordar a concepção do labor pictórico em um tempo/espaço permeado pela ressignificação da prática articulada ao saber teórico, ao conceito de experiência, instaurado por Dewey (2010), bem como ponderar sobre o conceito do espaço do estúdio como um laboratório de ensino e aprendizagem da linguagem pictórica. Para tanto, passa-se da experiência solitária no espaço que configura o ato da produção ao saber oriundo do acúmulo da tradição sobre a pintura e, finalmente, tece-se a experiência singular em um fenômeno epistemológico, que confere singularidade à práxis de viver um saber pictórico próximo à percepção de ensino e aprendizagem, sobretudo quando o espaço de criação é compartilhado.

Entre as metodologias operativas do espaço do estúdio, ancora-se como base da experiência a concepção da produção de sentido na ação, que engloba gestos, emoções e estratégias que perpassam o processo criativo na criação de imagens, conceitos e meios. Conforme exposto por Lampert e Wosniak (2016), a noção de Arte reportada por Dewey reside na articulação que a criatura viva tem com seu ambiente, pois o naturalismo deweyiano torna-se necessidade para a Arte. Neste sentido, a função da Arte é unificar a vitalidade consciente presente na vida humana, pois as obras de Arte qualificadas não geram experiências estéticas especializadas. A experiência estética é responsável por amplificar todas as 
inquietações humanas. É na integração entre o pensamento e o instrumento de expressão - ou entre a pintura, seus objetos e fazeres poéticos, dentre estes as estruturas que engendram seu espaço de concepção, ensino e aprendizagem que se pode esboçar a comunicação a respeito da experiência singular/estética. Dessa relação brotam conflitos, resistências e impressões. Destes elementos, por sua vez, emergem as experiências, envoltas em ideias e emoções.

Sobre Arte e Educação, o livro Studio Thinking, de Hetland et al. (2007), apresenta a perspectiva da sala de aula de Artes Visuais pensada como estúdio. De acordo com Lampert (2016), esta perspectiva não é entendida como comparação destes espaços, mas como a articulação dos mesmos, sendo que em ambos (aparentemente distantes) desenvolvem-se procedimentos metodológicos semelhantes. Pondera-se o espaço da sala de aula como gerador similar ao estúdio, em consonância com possibilidades para ensino e aprendizagem em Artes Visuais. Desta forma, Arte e Arte Educação ancoram-se sobre conjuntos de práticas que compreendem o saber fazer, a autorreflexão, o contexto sociocultural e abordagens históricas, que envolvem a prática pedagógica e a prática artística como procedimentos de um processo criativo evidenciado pela construção sistemática de experiências. Refletir sobre propostas de ensino e aprendizagem que relacionem teoria e prática é relevante para conectar a subjetividade da prática docente e o próprio processo formativo, usando o espaço do ateliê híbrido como eixo e cartografia, como meios de metodologia ou caminhos a serem percorridos como possibilidade de investigação. Desta forma, é possível centrar a pesquisa educativa baseada em Arte, já que aquela constitui uma base de prática artística que permeia a articulação entre ensino e aprendizagem na educação pela pintura.

\section{O GRUPO DE ESTUDOS ESTÚDIO DE PINTURA APOTHEKE OU UM ESTUDO DE CASO COMO ESPAÇO E TEMPO PARA A PESQUISA EM ARTE NA ARTE EDUCAÇÃO ${ }^{1}$}

Partindo do entrelace do conceito de experiência (Dewey, 2010) e da perspectiva da pesquisa em Arte, a investigação desenvolvida (e ainda em andamento, mas que já possibilita reflexões) que apresentamos neste artigo tange três perspectivas operativas para o trabalho no ateliê - nomeadamente, os encontros semanais do Grupo de Estudos Estúdio de Pintura Apotheke², as residências artísticas e as micropráticas desenvolvidas em aulas abertas de Artes Visuais na Universidade. Essas ações abordam também o conceito de Salles (2014) referente às redes de criação. 0 autor discorre sobre o inacabamento, o deslocamento da pesquisa, as interações e possibilidades na concepção da obra. 0 conceito de rede, quando associado à sua imagem, propõe pontos de encontro, de relação/
1. Parte deste texto foi publicado e apresentado no 26 Encontro da Associação Nacional de Pesquisadores em Artes Plásticas - ANPAP em Campinas/SP - Brasil no ano de 2017. 2. O Programa de extensão 'Grupo de Estudos Estúdio de Pintura Apotheke', fundado no ano de 2014, oferece oficinas, minicursos, palestras, aulas abertas e residências artísticas que envol-vem a temática da pintura para estudantes de Graduação, PósGraduação e a comunidade acadêmica e externa. Desta forma, oportuniza um espaço para conhecimento e aprofundamen-to de determinadas técnicas e do processo pictórico, bem como conversas e trocas de saberes com artistas com conhecimento e notoriedade no meio artístico. Para conhecer, acesse: http://www. apothekeestudiodepintura.com 
articulação e tangenciamento entre ideia e conteúdo, bem como entre o fazer e o saber. Os movimentos do crescer e interagir não podem ser dissociados, pois sua consolidação depende necessariamente de sua associação. Uma rede só se expande quando tece uma nova interação entre seus fios. Metaforicamente, tais interações podem constituir os próprios momentos de reflexão em que as coisas, ao interagirem, de fato se encostam e propõem trocas entre si. É nessa perspectiva de busca de contato na trama do artista professor que as três ações estão sendo estabelecidas.

Durante o ano de 2016, o Grupo de Estudos Estúdio de Pintura Apotheke realizou dezesseis encontros de estudos sobre o livro Interação da cor (2009), de Josef Albers. Os estudos pautaram-se em práxis artísticas e reflexões teóricas quanto ao uso dos exercícios como testes de um processo, em vez de um trabalho final (obra). Concomitante aos exercícios, buscou-se o desenvolvimento do que intitulamos de Projeto Albers ${ }^{2}$, no qual cada participante deteve seu processo criativo e suas redes de criação específicas, expandindo as propostas iniciais do Grupo. Nesta plataforma, foram construídos subprojetos como o Albers Box (material didático para fins de uso em estudos cromáticos); as Cartelas de Escalas de Valores (material didático para fins de uso em estudos cromáticos), construídas em diferentes materiais (plástico, transparência, texturas), além de um Catálogo de Estudos que registrou, como um diário, todos os exercícios realizados pelos participantes do Grupo.

Dos encontros e pesquisas realizadas pelo Grupo de Estudos partem ações pontuais que objetivam o aprofundamento pessoal artístico na vertente da pesquisa em Arte e Arte Educação. As residências artísticas desenvolvidas no ateliê de pintura da Universidade do Estado de Santa Catarina (UDESC), no primeiro semestre de 2017, são um exemplo deste aprofundamento, pois colaboram para a construção do pensamento visual, de modo que este interaja com o que lhe é externo, e de suas relações internas enquanto processo. As proposições aos residentes visavam possibilitar o aprofundamento de suas pesquisas e estudos sobre suas práticas e poéticas, evidenciando o aprofundamento da poética e retórica sobre o trabalho pictórico. Até o momento, foram desenvolvidas três residências que versam sobre a pintura no âmbito contemporâneo, ou seja, que compreendem seu campo expandido e suas referências. As residências artísticas propuseram um mergulho no processo criativo; um olhar voltado ao espaço inventivo. Percebe-se que estas trazem à tona os processos de desenvolvimento de obras, suas redes criativas e, assim, transformam em processo o que é experienciado pelo artista (ou professor). As residências foram desenvolvidas com base em projetos (com planejamentos) para tempo e espaço de um estudo vertical na linguagem pictórica em articulação e consonância com outras linguagens contemporâneas e em turno inverso ao período escolar. Participaram do projeto 
de residência artística a artista professora Claudia Del Rio (Rosário - Argentina), alunos de Pós-Graduação e Graduação em Artes Visuais da própria UDESC e professores da rede pública da cidade de Florianópolis e Curitiba.

Apontando para outra metodologia operativa no estúdio de pintura, instaurou-se o termo microprática. Desenvolvido por Lampert e adotado nas ações do Grupo de Estudos, refere-se ao estúdio como prática de pesquisa de Graeme Sullivan (2005) e à teoria clínica de Zeichner (2013). Nesse entendimento, compreende-se a formação do artista professor, na qual há um método em que indivíduos e grupos usam um caminho indutivo e métodos performativos para encontrar e resolver problemas, avaliar e decretar mudanças, criticar e criar novas práticas. Assim, micropráticas são desenvolvidas como planejamento de uma aula em que a prática artística instiga o estudante a resolver e formular problemas, durante um período de aproximadamente quatro horas, e ocorrem no espaço do estúdio de pintura, geralmente em turno inverso ao período escolar. Não seguem o estudos de técnicas, mas norteiam-se pelo objetivo de articular o processo criativo ao processo pedagógico, bem como pensar o campo da pintura de forma vertical em um conjunto de reformulações de teorias e práticas, na perspectiva de gerar e abrir novos desafios sobre o processo pictórico. As micropráticas propostas pelo Grupo de Estudos Estúdio de Pintura Apotheke acontecem em duas vertentes, vinculadas ao contexto da Universidade, e funcionam de forma semelhante às "oficinas, workshops ou cursos de curta duração", e não como disciplinas. Trabalha-se com espacialidade expandida para além de suportes tradicionais, não como um estudo de técnica ou leitura de manual, mas tratando a pintura como um meio para narrativas poéticas ou para a construção de um pensamento visual, que pode interrogar o próprio tempo da pintura. Em uma microprática situa-se o saber/fazer/agir na resolução e busca de problemas que envolvem o planejamento, metodologia performativa e avaliação do trabalho docente e do próprio trabalho que é realizado como Arte.

Portanto, conforme Lampert (2016), parte-se do contexto de que todo objeto artístico poderá ter dimensões políticas, discursivas e pedagógicas; compreende-se a prática no estúdio de pintura como processo de um fazer criativo no qual se inclui a reflexão crítica e a produção plástica por meio da experimentação (e vice-versa), concebendo que a pintura poderá ser uma representação imaginária, mas que também denota incontestavelmente derivações sobre a estética. Tais reflexões sobre as concepções didático-pedagógicas decorrem dos estudos da Arte como experiência, seja como teoria ou abordagem metodológica, compreendendo o estúdio de pintura como um laboratório, a exemplo do que Dewey objetivava para sua escola-laboratório. Assim, o Estúdio de Pintura Apotheke é, na concepção de sua palavra, um lugar de labor ou uma botica, onde situa-se o trabalho experimental e a experiência reflexiva e crítica. 
O desafio de teorizar a prática de ateliê requer a construção de uma estrutura robusta e defensiva para considerar a relação entre as teorias e as práticas, que intuem como a Arte é feita (produzida) e como pode ser estudada e aprendida. A necessidade de se exercer cautela na descrição de uma estrutura analítica para teorizar a prática artística como um lugar para a pesquisa é evidente. Qualquer estrutura sistemática tem o potencial de conduzir a uma nova ortodoxia na forma de interesses preferidos e funções de métodos para normalizar práticas (justamente o contrário do que Dewey pressupunha). A experiência no ateliê de pintura pode ser uma forma de investigação cognitiva. Conforme Sullivan (2004), este é o local onde a pesquisa pode ser empreendida de forma suficientemente robusta e forte, para produzir conhecimento e compreensão, onde é transformadora, confiável, e social e culturalmente relevante para o contexto da produção artística e o debate sobre o tempo da pintura, assim como poderá ser o locus da consequência educacional de práticas que oferecem resultados e inclinam-se à mudança em relação a diferentes circunstâncias socioculturais. Trata-se de um lugar repleto de ideias e imagens que informam ações individuais, sociais e culturais. Sobretudo na sequência do ensaio iconoclasta de Daniel Buren, bem como da notícia de que John Baldessari ministrava aulas de "Post-Studio Art" na CalArts (Instituto de Artes de California - EUA), nos anos 1970, surgiram discussões sobre a morte e a obsolescência do estúdio para o artista. No entanto, artistas contemporâneos são comparados a Rubens, como exemplo de J. Koons, quando visitado por críticos, - naturalmente não por sua atuação como pintor, mas sim pela forma operativa como trabalha em seu estúdio, com assistentes e diversos projetos em andamento. O Estúdio passou de um lugar individual e solitário, da torre de marfim, a um lugar familiar, para um lugar colaborativo, que ora ainda remete a um espaço privado, ora a uma aula ateliê, com ênfase na originalidade artística na criação do objeto. Por fim, chega ao status do lugar da arte pós-estúdio (embora ainda se tenha um espaço e tempo de produção), quando a produção artística trata da esfera da produção e colaboração. Mesmo assim, ainda é um espaço de labor das ideias (ou feitura delas). Não se trata de trazer à tona a topografia do lugar do estúdio na História da Arte, embora isto seja relevante e já tenha sido objeto de análise por John Elderfield (2015), com exposição realizada na Gagosian Gallery em NY, nos EUA. Além deste mapeamento, buscamos, neste momento da pesquisa, desenvolver ações que perpassem a criação e resolução do trabalho pictórico em um tempo e espaço de ensino e aprendizagem, no contexto do que é a Educação pela pintura.

O Estúdio de Pintura Apotheke, a partir do ano de 2018, vem procurando desenvolver uma convocatória para acolher projetos que pairem sobre o estudo do processo pictórico para além do condicionamento técnico e em articulação da orientação de trabalho prático e teórico, ou ainda reflexivo, sobre o lugar da pintura em nosso contexto - no caso, a Universidade. 


\section{REFERÊNCIAS}

BUREN, Daniel. "The Function of the Studio". In: October, Cambridge, Fall 1979, n 10, pp.51-58. Disponível em: $<$ <ttp://bortolamigallery.com/artist/daniel-buren/writings/>. Acesso em: 20 maio 2017.

DEWEY, John. Arte como experiência. São Paulo: Martins Fontes, 2010.

JESUS, Joaquim Alberto Luz de. (IN)VISIBILIDADES: um estudo sobre o devir do pro-fessor-artista no ensino em artes visuais. 2013. 260 f. Tese de Doutoramento em Educação Artística - Faculdade de Belas Artes, Universidade do Porto, Por-tugal. 2013.

. O professor-artista como vírus. Revista Apotheke e-periódico, Florianópolis, v. 3, n. 2, ano 2, jul. 2016. Disponível em: <http://revista.udesc.br/index.php/ APOTHEKE/index>. Acesso em: 01 ago. 2016. pp. 28-43.

LAMPERT, Jociele. [Entre paisagens] ou sobre 'ser' artista professor. In: Cadernos de Pesquisa - Pensamento Educacional. Revista do Programa de Pós-Graduação em Educação UTP. DOSSIÊ: ARTE E EDUCAÇÃO: ABORDAGENS E PERSPECTIVAS. Paraná: Curitiba, 2016, vol. 11, no 29.

ISSN: 2175-2613. Disponível em: <http://seer.utp.br/index.php/a/ index>. Acesso em: 05 maio 2017.

LAMPERT,Jociele. ArteContemporânea, cultura visual e formação docente. 2009.159f. Tese (Doutorado Escola de Comunicações e Artes - ECA) Programa de Pós-Graduação em Artes Visuais, Universidade de São Paulo, São Paulo, SP.

SALLES, Cecilia Almeida. Redes da Criação: construção da obra de arte. 2. ed. São Paulo: Horizonte, 2014.

SULLIVAN, G. Art Practice as Research: Inquiry in Visual Arts. Thousand Oaks, CA: Sage, 2005. . Studio Art as Research Practice. In: Handbook of Research and Policy in Art Education, edited by Elliot Eisner, Michael D. Day, A Project of the National Art Education Association, New Jersey/USA: Copyright, 2004. pp. 795-814.

WOSNIAK, F.; LAMPERT, Jociele. Sobre o ensino/aprendizagem em Artes Visuais ou arte como experiência. In: Seminário comemorativo do centenário do livro de-mocracia e educação, 2016, São Paulo. Seminário comemorativo do centená-rio do livro Democracia e Educação: a Filosofia da Educação de John Dewey em debate. Paraná: Londrina, 2016, vol. 1. pp. 39-54. Disponível em: <http://www.uel.br/ eventos/centenariode/>. ISBN978-85-7846-365-6. Acesso em: 08 maio 2016.

ZEICHNER, Kenneth M. Políticas de formação de professores nos Estados Unidos: como e porque elas afetam vários países no mundo. Autêntica Editora: Belo Horizonte, 2013.

\section{Jociele Lampert}

Desenvolveu pesquisa como professora visitante no Teachers College na Columbia University, na cidade de Nova York, como Bolsista Fulbright (2013), onde realizou es-tudo intitulado: ARTIST'S DIARY AND PROFESSOR'S DIARY: ROAMINGS ABOUT PAINTING EDUCATION. Possui Graduação em Desenho e Plástica - Bacharelado em Pintura pela Universidade Federal de Santa Maria (2002) e Graduação em Dese-nho e Plástica - Licenciatura pela Universidade Federal de Santa Maria (2003); Mestre em Educação pela UFSM (2005); Doutora em Artes Visuais pela ECA/USP (2009). Professora Associada na Universidade do Estado de Santa Catarina. Foi Coordenadora de Estágio CEART/UDESC (2006-2009); Foi Chefe de Departamento de Artes Visuais DAV/CEART/UDESC (2009-2011); Coordenadora do PIBID/CAPES/UDESC da área de Artes Visuais (2011-2016). Foi Coordenadora de Pós-Graduação em Artes Visuais Mestrado e Doutorado PPGAV/CEART/ UDESC (2015) e Coordenadora de Pós-Graduação da UDESC (2016). Atua no Mestrado e Doutorado em Artes Visuais PPGAV/UDESC como orientadora na Linha de Pesquisa de Ensino de Arte e na Gra-duação em Artes Visuais DAV/UDESC. É membro do Grupo de Estudos e Pesquisa em Arte, Educação e Cultura UFSM/CNPq; Membro/Líder do Grupo de Pesquisa Entre Paisagens UDESC/CNPq; Coordenadora do Grupo de Estudos Estúdio de Pintura Apotheke (UDESC). É Editora Chefe do Periódico Revista Apotheke. Tem experiência na área de Artes Visuais, atuando principalmente nos seguintes temas: pintura, arte e educação, formação docente. É membro associado da ANPAP. Site: www. jocielelampert.com.br

(*) Texto enviado em abril de 2018 